\title{
Investigation of Catalytic Property of Plant Mediated Silver Nanoparticles as Degradation of Toxic Dyes in Water
}

\author{
Satish Chandra Sati ${ }^{1} \cdot$ Ankit Singh Bartwal ${ }^{1 *} \cdot$ Sumit Ringwal $^{1} \cdot$ Gurpreet Kour $^{1} \cdot \operatorname{Rashmi} \operatorname{Rawat}^{2} \bullet$ \\ S C Nautiyal ${ }^{3}$ \\ ${ }^{1}$ Department of Chemistry, H.N.B. Garhwal University (A Central University) Srinagar Garhwal, Uttarakhand, \\ India-246174 \\ ${ }^{2}$ Department of Chemistry, HNB Garhwal University, BGR Campus Pauri, Pauri (Garhwal), Uttarakhand, India- \\ 246001 \\ ${ }^{3}$ Department of Physics, Govt. Degree College, Maldevta, Dehradun, India-248001
}

*Corresponding author Email: anki.8551@gamil.com

Received: 2.8.2021; Revised: 16.9.2021; Accepted: 19.9.2021

CSociety for Himalayan Action Research and Development

\begin{abstract}
Nowadays, silver nano-compounds mediated by plant materials are widely used material in daily life chemistry as well as across the industries, medical, electronics, ceramics, and in all research fields, because it has some specific characteristics such as non-toxic, inexpensive, nature-friendly, heat resistant, catalytic activity, high electric conductivity and so on. In the present work we reported the photo-catalytic dye degradation of green synthesized silver nanoparticles of size $43.75 \mathrm{~nm}$ by using the flowers extract of Rhododendron campanulatum tree. Synthesized AgNPs have worked as a strong nano-catalyst for the degradation of toxic dyes such as malachite green (MG), and acridine orange (AO). As a catalyst, synthesized AgNPs degraded the malachite green (MG) dye 47.22 \% within $90 \mathrm{~min}$, and acridine orange (AO) dye $66.16 \%$ in $4 \mathrm{~h}$ of solar irradiation, while in the absence of nanocatalyst, MG and AO dye degraded upto $22.13 \%$ in $90 \mathrm{~min}$ and $46.75 \%$ in $4 \mathrm{~h}$ of photo-irradiation respectively. Synthesized nano material (AgNPs) may be applicable as a strong catalytic agent for the degradation of toxic dyes, water purifying agent as well as a good antioxidant agent.
\end{abstract}

Keywords: Rhododendron campanulatum; green synthesis; AgNPs; catalytic degradation; malachite green; acridine orange.

\section{Introduction}

In the 21st century, the use of nanotechnology (Sati et.al., 2020a; Ravichandran et.al., 2016) is playing a vital role in the field of chemical sustainability by using the various type of stabilizing agents such as plant material, fungi, algae etc. in the synthesis procedure. The green synthesis of nanomaterial is a new era of science and technology for the development of novel material due to its easy approach and compatibility with nature, which is the requirement of present scenario. Nowadays, green synthesized nanomaterials are using as a toxic chemical remover, water purifying agents, nano-biosensors, nano-medicines, detoxifying agents, and many more (Naginov et.al., 2009; Maier et.al., 2001; Anker et.al., 2010; Arvizo et.al., 2012; Bhattarai et.al., 2018). Green mediated nanomaterial from plants, replace the toxic chemical reactants (Calderon et.al., 2020) 
and employing biological materials in the form of enhanced properties which are more it has some specific characteristics such as non-toxic, inexpensive, nature friendly, heat resistant, catalytic activity, highly efficient, reproducible, high electric conductivity and allow welldefined shape and size (Nagajyothi et.al., 2015; Pan et.al., 2020). In the present scenario, the formation of many toxic, non-biodegradable and hazardous chemical compounds are grim point of discussion, which may pollute major components of our environment as air pollutant, water pollution, ecology pollutant, etc. (Galindo et.al., 2001; Herrmann et.al., 1999). Therefore the main focuses of researchers on detoxification and recycling of waste-water by solar-catalytic treatment by applying nanomaterial (Freudenhammer et.al., 1997).

In the present work we have focused on the development of such nanomaterial which has excellent physio-chemical and bioactive properties like antibacterial, bio-sensing, photocatalytic, optical, antioxidant, catalytic properties, antimicrobial, drug delivery, and so on, even nanoparticles used as an inhibiter as well as antiviral agent against the concerned viruses (Kim et.al., 2006; Haryono et.al., 2008; Roy et.al., 2015; Suprihatin et.al., 2020; Bartwal et.al., 2020a). The novelty of this work is the development of an excellent nano catalyst as silver nanomaterial by using the flowers extract of Rhododendron campanulatum tree of Tungnath, a Garhwal region of Uttarakhand, which was performed the first time by using this plant material as a source of phyto-chemicals and reducing as well as the capping agent. This plant has the richness of phenolic compounds for significant anti-oxidant activity (Painuli et.al., 2018), lots of medicinal properties like useful in cold, sciatica, hemicranias, digestive, respiratory disorders, boils, cough, headache, tonic, fever and so on (Bartwal et.al., 2020b). Plants represent a potential source of bioactive constituents like alkaloids, flavonoids, tannins, phenolic compounds, etc. having antioxidant properties with fewer side effects. Antioxidants like vitamin $\mathrm{C}$, vitamin $\mathrm{E}$, polyphenols, lycopene, etc. present in many medicinal plants which helps in neutralizing the free radicals $(\mathrm{AB}$ et.al., 2015; Sati et.al., 2020b; Tripathi et.al., 2019). As per the previous literature we have seen that most of the silver nanoparticles (AgNPs) showed excellent catalytic activity for the degradation of textile or toxic dyes such as congo-red methyl orange, rose bengal, alizarin red, acridine orange, malachite green, and many more (Sati et.al., 2018).

\section{Materials and methods}

\section{Chemicals}

$\mathrm{AgNO}_{3}$, malachite green (MG) and acridine orange (AO) dyes of Sigma Aldrich and flowers of Rhododendron campanulatum (Fig.1) from the Tungnath region of Garhwal Himalaya, Uttarakhand were utilized for this study.

\section{Methodology}


Preparation of silver nanoparticles (AgNPs) takes place via green root chemistry without using any stabilizing agents, in which freshly prepared flowers extract of $R$. campanulatum (Bartwal et.al., 2020b) were used. Protocol of AgNPs synthesis was followed by our previous article Bartwal et.al. 2020b. Thereafter, green synthesized AgNPs were characterized by different instrumental techniques such as UV double beam spectrophotometer, XRD, SEMEDX, BET isotherm and TEM (Kim et.al., 2006; Bartwal et.al., 2020b).

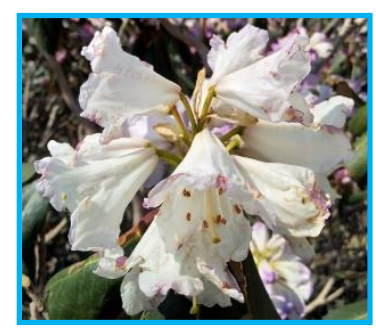

Fig.1: Flowers of R. campanulatum (RCF)

\section{Determination of Catalytic activity}

To evaluate the photo catalytic activity, $10 \mathrm{mg}$ of synthesized AgNPs, were added to each 100 $\mathrm{mL}$ aqueous solution malachite green (MG) and acridine orange (AO) dyes separately. Then both solutions were continuously stirred in dark condition for $1 \mathrm{~h}$ to ensure the surface equilibrium between the AgNPs and dye (MG and $\mathrm{AO}$ ) solutions. Thereafter both dye solutions were irradiated in the presence of visible light, and then the characteristic absorption spectra of dyes were recorded on the UV spectrophotometer using deionized water as a standard reference (Tripathi et.al., 2019; Yulizar et.al., 2019; Aziz et.al., 2015; Bogireddy et.al., 2016). Calibration curves were used to calculate the concentrations of dyes.

The dye degradation efficiency of synthesized nanomaterial (AgNPs) was calculated by the following formula:

\section{Degradation $\left.(\%)=\left[\mathrm{C}_{0}-\mathrm{C}_{\mathrm{t}}\right) / \mathrm{C}_{0}\right] \times 100$}

Where;

$\mathrm{C}_{\mathrm{o}}$ and $\mathrm{C}_{\mathrm{t}}$ are the concentration of dyes at time $\mathbf{t}$ $=\mathbf{0}$ and $\mathbf{t}$ after solar irradiation respectively.

\section{Results and discussion}

\section{Characterization of silver nanoparticles}

The green synthesized metal nanoparticles (AgNP) were characterized by several instruments, such as UV spectrophotometer (model 3375 Electronics India), in which the characteristic absorption maxima peak of silver was appeared at $472 \mathrm{~nm}$, XRD (PAN alytical, X'PERT PRO) diffraction peaks at $2 \theta$ values of $37^{\circ}, 43^{\circ}$, and $63^{\circ}$ for the planes (111), (200), and (220) respectively, in which the mean crystal size of green AgNPs was calculated to be approximately $22.97 \mathrm{~nm}$. Synthesized AgNPs were agglomerated, smooth in morphology and irregular shaped, and it was indicated by SEM and TEM images in which the average grain size was calculated $43.75 \mathrm{~nm}$. To confirm the presence of metallic AgNPs, elemental analysis EDX was done, in which significant presence of silver $(69.14 \%)$ was found with other elements as oxygen $(22.24 \%)$ and carbon $(8.62 \%)$ (Sati 
et.al., 2020a; Kim et.al., 2006; Bartwal et.al., 2020b). The BET isotherm study of the synthesized sample revealed that a single point surface area (at P/Po) of NPs was $0.1398 \mathrm{~m}^{2} / \mathrm{gm}$ and BET surface area was $0.1057 \mathrm{~m}^{2} / \mathrm{gm}$ (Murugadoss et.al., 2021).

\section{Determination of Catalytic activity}

Catalytic degradation of malachite green and acridine orange dye was investigated by UV spectrometer, in which as the time of solar irradiation increases the UV plot of MG and $\mathrm{AO}$ dyes show the hypochromic shift in the characteristic peaks of the standard solution of dye. The hypochromic shift in the characteristic peak of MG and AO dyes indicates the dye

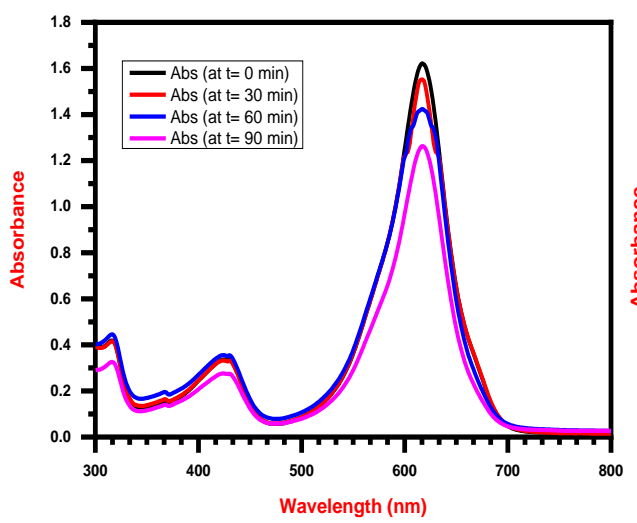

(a) degradation process in the presence of catalyst and without catalyst. The amount of dye degradation was calculated, it shows $22.13 \%$ degradation of malachite green dye in the absence of nano catalyst (AgNPs), while AgNPs degraded $47.22 \%$ in 90 min of solar irradiation which are shown in Fig.2(a) and Fig.2(b) respectively. These results clearly indicate that the MG dye degraded very sharply in the presence of synthesized AgNPs while this degradation was very slow in the absence of AgNPs (Tripathi et.al., 2019; Sati et.al., 2018; Yulizar et.al., 2019; Aziz et.al., 2015; Bogireddy et.al., 2016).

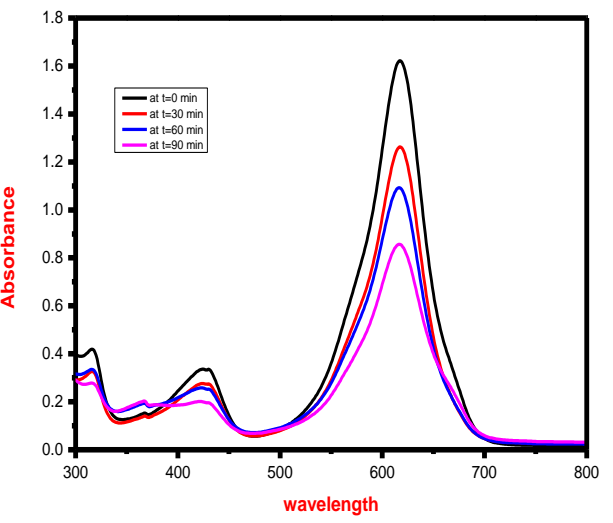

(b)

Fig.2: Degradation of MG dye (a) without AgNPs, and (b) with AgNPs as catalyst

Similarly, in the photo-catalytic degradation of acridine orange (AO) dye, it also catalyzed by synthesized AgNPs. The UV graph exhibited a decrease in the absorption maxima peak of $\mathrm{AO}$ dye within $4 \mathrm{~h}$ of sun light irradiation. In the investigation of the catalytic degradation of $\mathrm{AO}$ dye, it was degraded upto $66.16 \%$ degradation in the presence of synthesized AgNPs within 4h, [see Fig.3(b)], while in the absence of AgNPs, it is found that the nano catalyst degraded the AO dye $46.75 \%$ of the initial amount in $4 \mathrm{~h}$ of photo irradiation [Fig.3(a)], which is observed by the UV-Visible spectrophotometer. These results clearly indicate that $\mathrm{MG}$ and $\mathrm{AO}$ dyes degraded rapidly in the presence of green synthesized nano-catalyst (Tripathi et.al., 2019; Sati et.al., 
2018; Yulizar et.al., 2019; Aziz et.al., 2015; Bogireddy et.al., 2016). Therefore, it is concluded that green synthesized AgNPs

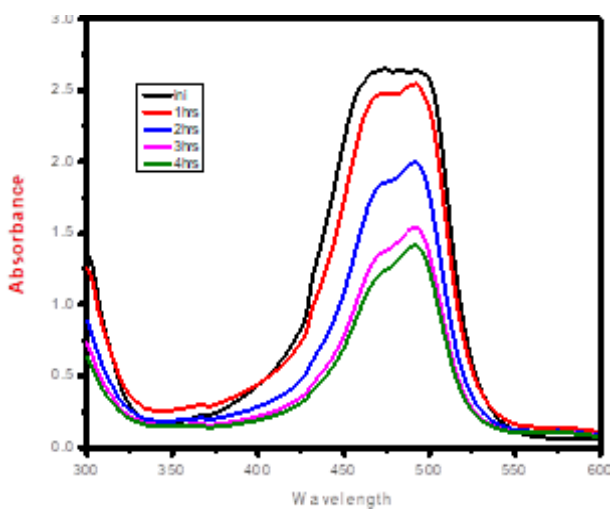

(a) showed excellent catalytic property for the degradation of toxic or textile dyes.

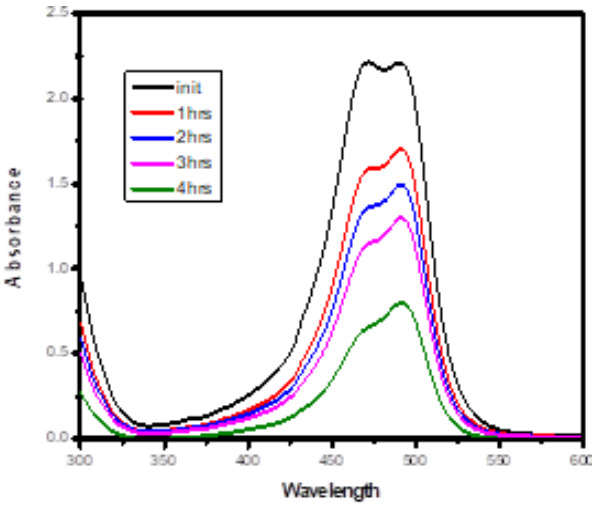

(b)

Fig.3: Degradation of AO dye (a) without AgNPs, and (b) with AgNPs as catalyst

\section{Conclusion}

In the present study, AgNPs were synthesized via inexpensive and nature friendly root by using the flowers extract of R.campanulatum, in which the obtained average size of synthesized NPs was $43.75 \mathrm{~nm}$. In the application part of nanomaterial, synthesized nanomaterial (AgNPs) was active for the catalytic degradation of toxic dyes, which showed excellent catalytic property in the photo-degradation of malachite green (MG) and acridine orange (AO) dyes. The MG dye was degraded $47.22 \%$ in the presence of AgNPs, while in the absence of nano catalyst (AgNPs) it shows $22.13 \%$ degradation in $90 \mathrm{~min}$ of visible light irradiation. Similarly, the AO dye degraded $66.16 \%$ in the presence of AgNPs and degraded $46.75 \%$ in the absence of AgNPs within the time period of 4 hours of visible light irradiation. As increasing the time period of visible light irradiation upto $18-20 \mathrm{~h}$, the dye degradation reaches upto more than $90 \%$ with AgNPs. These evidences indicate that the green synthesized nanomaterial (AgNPs) have excellent catalytic property for the photo degradation of toxic or textile dyes. So, we can conclude that synthesized nanomaterial may be applicable in the field of anti-corrosion, antioxidant, water purifying agent as a removal of toxic contaminants as well as a dye degrading agent in many industries of drugs, electronics, cosmetics, ceramics and so on.

\section{Acknowledgements}

Authors are pleased to acknowledge Dept. of USIC, HNB Garhwal University (for SEM, XRD) and IIP Dehradun (BET) for providing required facilities to carry out this work.

\section{References}

AB SB, Lepcha R and Tamang D (2015). Bioactive compounds and antioxidant 
properties of tea: status, global research and potentialities; Journal of Tea Science Research; 5.

Anker JN, Hall WP, Lyandres O, Shah NC, Zhao J and Van DRP (2010). Biosensing with plasmonic nanosensors; Nanoscience and Technology: A Collection of Reviews from Nature Journals; pp.308-319.

Arvizo RR, Bhattacharyya S, Kudgus RA, Giri $K$, Bhattacharya $\mathrm{R}$ and Mukherjee $\mathrm{P}$ (2012). Intrinsic therapeutic applications of noble metal nanoparticles: past, present and future; Chemical Society Reviews; 41(7); pp.2943-2970.

Aziz N, Faraz M, Pandey R, Shakir M, Fatma T, Varma A, Barman I and Prasad R (2015). Facile algae-derived route to biogenic silver nanoparticles: synthesis, antibacterial, and photocatalytic properties; Langmuir; 31(42); pp.1160511612.

Bartwal AS, Thakur R and Sati SC (2020a). A review on viruses, nanoparticles and their effects on mankind. Virus economy (Series IV), Innov. Sol. Lab publication; 4; pp.67-78.

Bartwal AS and Sati SC (2020b). Biosynthesis of silver nanoparticles from flowers of Rhododendron campanulatum tree of Tungnath Himalaya; Applied Innovative research; 2(1); pp.39-43.

Bhattarai B, Zaker, Y and Bigioni TP (2018). Green synthesis of gold and silver nanoparticles: Challenges and opportunities. Current Opinion in Green and Sustainable Chemistry; 12 ;pp.91100.

Bogireddy NKR, Kumar HAK and Mandal BK (2016). Bio-fabricated silver nanoparticles as green catalyst in the degradation of different textile dyes; Journal of environmental chemical engineering; 4(1); pp.56-64.

Calderon-Ayala G, Cortez-Valadez M, Martínez-Nunez CE and Flores-Acosta M (2020). FLG/silver nanoparticles: Nanocomposite by green synthesis. Diamond and Related Materials; 101; 107618.

Freudenhammer H, Bahnemann D, Bousselmi L, Geissen SV, Ghrabi A, Saleh F, Si-Salah A, Siemon V and Vogelpohln A (1997). Detoxification and recycling of waste water by solar-catalytic treatment; Water Science and Technology; 35(4); pp.149156.

Galindo C, Jacques P and Kalt A (2001). Photooxidation of the phenylazonaphthol $\mathrm{AO}_{20}$ on $\mathrm{TiO}_{2}$ : kinetic and mechanistic investigations; Chemosphere; 45(6-7); pp.997-1005.

Haryono A, Sondari D, Harnami SB and Randy M (2008). Sistesa Nanopartikel Perak Dan Potensi Aplikasinya; Journal of Industrial Research; 2(3); pp.156-163.

Herrmann JM (1999). Heterogeneous photocatalysis: fundamentals and applications to the removal of various types of aqueous pollutants; Catalysis today; 53(1); pp.115-129.

Kim D, Jeong S and Moon J (2006). Synthesis of silver nanoparticles using the polyol process and the influence of precursor injection; Nanotechnology; 17(16); pp.4019.

Maier SA, Brongersma ML, Kik PG, Meltzer S, Requicha AA and Atwater HA (2001). Plasmonics-a route to nanoscale optical devices. Advanced materials; 13(19); pp.1501-1505.

Murugadoss, G., Kumar, D.D., Kumar, M.R., Venkatesh, N. and Sakthivel, P., 2021. Silver decorated $\mathrm{CeO}_{2}$ nanoparticles for rapid photocatalytic degradation of textile rose bengal dye. Scientific Reports, 11(1), pp.1-13.

Nagajyothi PC, Cha SJ, Yang IJ, Sreekanth TVM, Kim KJ and Shin HM (2015). Antioxidant and anti-inflammatory activities of zinc oxide nanoparticles synthesized using Polygala tenuifolia root extract; Journal of Photochemistry and Photobiology B: Biology; 146; 1017. 
Noginov MA, Zhu G, Belgrave AM, Bakker R, Shalaev VM, Narimanov EE, Stout S, Herz E, Suteewong $T$ and Wiesner U (2009). Demonstration of a spaser-based nanolaser; Nature; 460(7259); pp.11101112.

Painuli S, Joshi S, Bhardwaj A, Meena RC, Misra K, Rai N and Kumar N (2018). In vitro antioxidant and anticancer activities of leaf extracts of Rhododendron arboreum and Rhododendron campanulatum from Uttarakhand region of India; Pharmacognosy

Magazine; 14(57); pp.294.

Pan Z, Lin Y, Sarkar B, Owens G and Chen Z (2020). Green synthesis of iron nanoparticles using red peanut skin extract: Synthesis mechanism, characterization and effect of conditions on chromium removal; Journal of colloid and interface science, 558, 106114.

Ravichandran V, Vasanthi S, Shalini S, Shah SAA and Harish R (2016). Green synthesis of silver nanoparticles using Atrocarpus altilis leaf extract and the study of their antimicrobial and antioxidant activity; Materials Letters; (180); pp.264-267.

Roy K, Sarkar CK and Ghosh CK (2015). Photocatalytic activity of biogenic silver nanoparticles synthesized using yeast (Saccharomyces extract; Applied cerevisiae) pp.953-959.
Sati SC, Tripathi PK and Sati MD (2018). Green Synthesis of Silver Nanoparticle from Leaves of Artemeisia roxburghiana L.; Journal of Applicable Chemistry. 7 (4); pp.835-842.

Sati SC, Kour G, Bartwal AS and Sati MD (2020a). Biosynthesis of Metal Nanoparticles from Leaves of Ficus palmata and Evaluation of Their Antiinflammatory and Anti-diabetic Activities; Biochemistry; 59(33); pp.3019-3025.

Sati SC, Bartwal AS and Aggarwal AK (2020b). Green synthesis of silver nanoparticles from Citrus medica peels and determination of its antioxidant activity; Applied Innovative research; 2(1); pp.56-60.

Suprihatin IE, Lestari GAD, Mardhani R and Edoway V (2020). Silver nanoparticles (AgNPs) as photocatalyst in the photodegradation of rhemazol brilliant blue; In IOP Conference Series: Materials Science and Engineering; 959(1); pp.012-018. IOP Publishing.

Tripathi PK and Sati SC (2019). Green synthesis of $\mathrm{Ag} / \mathrm{Cu}$ bimetallic nanoparticles and determination of it's antimicrobial and antioxidant activities; Journal of Emerging Technologies and Innovative Research 6 (4); pp.627-633.

Yulizar Y, Apriandanu DOB and Wibowo AP (2019). Plant extract mediated synthesis of $\mathrm{Au} / \mathrm{TiO}_{2}$ nanocomposite and its photocatalytic activity under sodium light irradiation; Composites Communications; $16 ; \quad$ pp.50-56. 